\title{
Preferential patterns of myocardial iron deposit by multislice multiecho T2* CMR in thalassemia major patients Vincenzo Positano*1, Antonella Meloni ${ }^{1}$, Alessia Pepe ${ }^{1}$, Pasquale Pepe ${ }^{1}$, Maria Chiara Dell'Amico ${ }^{1}$, Brunella Favilli ${ }^{1}$, Cristina Salvatori ${ }^{1}$, Petra Keilberg${ }^{1}$, Gennaro Restaino ${ }^{2}$, Eliana Cracolici ${ }^{3}$, Stefano Pulini ${ }^{4}$, Angela Ciancio ${ }^{5}$, Maria Filomena Santarelli ${ }^{1}$ and Massimo Lombardi ${ }^{1}$
}

Address: ${ }^{1} \mathrm{G}$ Monasterio Foundation and Institute of Clinical Physiology, CNR, Pisa, Italy, ${ }^{2}$ Università Cattolica del Sacro Cuore, Campobasso, Italy, ${ }^{3}$ Policlinico "Paolo Giaccone", Palermo, Italy, ${ }^{4}$ Osped. Civile "Spirito Santo", Pescara, Italy and 5 Ospedale "Madonna delle Grazie", Matera, Italy

* Corresponding author

from I3th Annual SCMR Scientific Sessions

Phoenix, AZ, USA. 21-24 January 2010

Published: 21 January 2010

Journal of Cardiovascular Magnetic Resonance 20 I0, I 2(Suppl I):P276 doi:I0.1 186/I532-429X-I2-SI-P276

This abstract is available from: http://jcmr-online.com/content//2/SI/P276

(C) 2010 Positano et al; licensee BioMed Central Ltd.

\section{Introduction}

T2* multislice multiecho cardiac magnetic resonance (CMR) technique has permitted quantification of myocardial iron burden by a segmental approach. Little is known in the literature about patterns of iron store in hemochromatosis.

\section{Purpose}

Our study aimed to investigate myocardial iron overload in thalassemia major (TM) patients by segmental $\mathrm{T} 2 *$ CMR technique, in order to determine if there were preferential patterns of iron deposit.

\section{Methods}

Five hundred and nineteen TM patients underwent CMR. Three short-axis views (basal, medium, and apical) of the left ventricle were acquired and analyzed using customwritten, previously validated software. The myocardium was automatically segmented into a 16-segment standardized LV model and the T2* value on each segment was calculated, as well as the global T2* value. Four different main circumferential regions (anterior, septal, inferior and lateral) were defined by averaging the corresponding segmental $\mathrm{T}_{2} *$ values.

\section{Results}

Two-hundred and twenty-nine patients showed global $\mathrm{T}^{*}$ value $<26 \mathrm{~ms}$, corresponding to significant global heart iron overload. The analysis was focused on this patient population, subsequently divided into two groups: severe iron overload $(\mathrm{N}=83$, global $\mathrm{T} 2 *<10 \mathrm{~ms})$ and mild-moderate iron overload $(\mathrm{N}=146$, global T2* between 10 and $26 \mathrm{~ms}$ ). For each group, segments were sorted by mean $\mathrm{T}^{*}$ value. Segment order was significantly preserved between the two groups $(\mathrm{r}=0.91, \mathrm{P}<$ 0.0001 ). Significant circumferential variability was found in patients with overall heart iron overload (figure $1 \mathrm{~A}$ ) as well as in both groups $(\mathrm{P}<0.0001)$. The mean $\mathrm{T} 2 *$ value over the anterior region was significantly lower than the mean $\mathrm{T} 2 *$ values over the other regions and the mean $\mathrm{T} 2 *$ over the inferior region was significantly lower than the $\mathrm{T} 2 *$ values over the septal and lateral regions (figure 1B). This pattern was preserved within each single slice (figure $1 \mathrm{C}$ ). We found a significantly higher $\mathrm{T}{ }^{*}$ value in the basal slice vs the medium and apical slices in patients with severe iron overload.

\section{Conclusion}

A preferential pattern of iron store in anterior and inferior regions appears to be present in TM patients with severe 

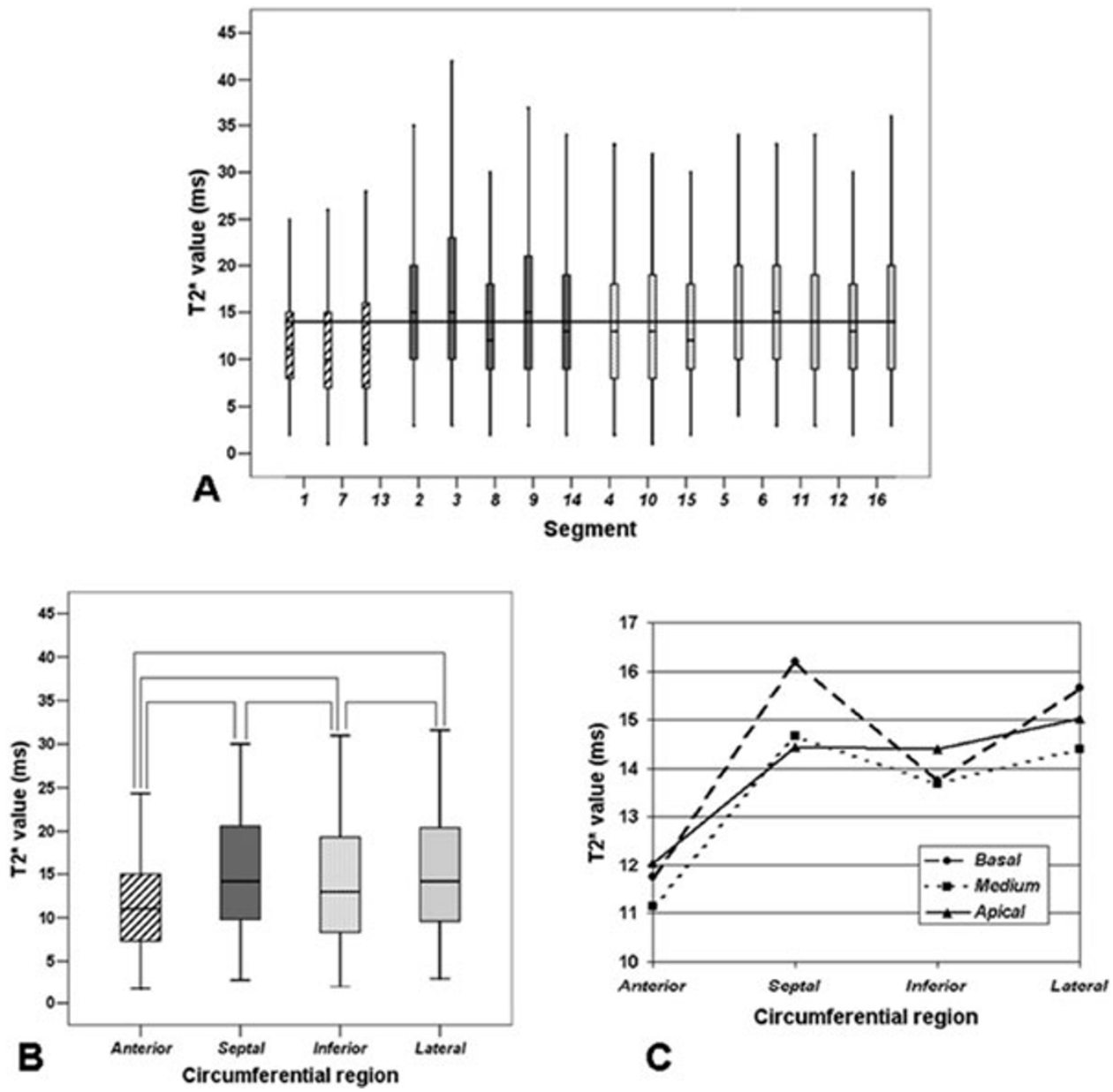

Figure I

Iron overload patterns: circumferential (A), longitudinal (B), slice-by-slice (C).

and mild-moderate iron overload. The preserved pattern between the groups prevents attributing this datum to additive susceptibility artefacts, which are negligible in heavily iron-loaded patients. A segmental T2* CMR approach could identify early iron deposit, useful for tailoring chelation therapy and preventing myocardial dysfunction in the clinical setting.
Publish with Biomed Central and every scientist can read your work free of charge

"BioMed Central will be the most significant development for disseminating the results of biomedical research in our lifetime." Sir Paul Nurse, Cancer Research UK

Your research papers will be:

- available free of charge to the entire biomedical community

- peer reviewed and published immediately upon acceptance

- cited in PubMed and archived on PubMed Central

- yours - you keep the copyright
BiolMedcentral 